\title{
Willingness to Engage in Traditional and Novel Depression Treatment Modalities Among Myocardial Infarction Survivors
}

\author{
Nathalie Moise, $M D, M S^{\top} \mathbb{D}$, Anusorn Thanataveerat, $\mathrm{MPH}^{7}$, \\ Ludwing Florez-Salamanca, $M D^{2,3}$, Siqin Ye, $M D, M S^{7}$, Min Qian, $P h D^{7}$, Megan Obi, $B A^{4}$, \\ and Carmela Alcantara, $P h D^{4,5}$
}

\begin{abstract}
${ }^{1}$ Center for Behavioral Cardiovascular Health, Division of Cardiology, Department of Medicine, Columbia University Medical Center, New York, NY, USA; ${ }^{2}$ Department of Biostatistics, Mailman School of Public Health, Columbia University, New York, NY, USA; ${ }^{3}$ Department of Psychiatry, Columbia University Medical Center, New York, NY, USA; ${ }^{4}$ Case Western Reserve University, Cleveland, OH, USA; ${ }^{5}$ The Columbia School of Social Work,

Columbia University, New York, NY, USA.
\end{abstract}

J Gen Intern Med 35(5):1620-2

DOI: $10.1007 / \mathrm{s} 11606-019-05406-8$

(c) Society of General Internal Medicine 2019

\section{INTRODUCTION}

Depression is a known risk factor for morbidity and mortality following myocardial infarction (MI). ${ }^{1}$ Several groups, including the American Heart Association, recommend depression screening and treatment post-MI. ${ }^{2}$ Yet, fewer post-MI survivors receive depression treatment than general depressed populations. ${ }^{3}$ To inform implementation efforts, we assessed depression treatment attitudes, acceptability, and willingness (by modality) among MI survivors with elevated depressive symptoms.

\section{METHODS}

From May 2013 to July 2013, YouGov, a non-partisan online polling firm, administered English and Spanish surveys to 1500 US opt-in survey panel participants reporting MI diagnosis by a healthcare professional. Sampling targets were based on age, sex, and race distribution of MI in the 2010 National Health Interview Survey (NHIS) using a two-step sample matching method that drew a random sample from the target population and then created a matched set of survey respondents to these marginals (response rates $45.8 \%$ English; $16.2 \%$ Spanish). ${ }^{3}$ We restricted analyses to participants with elevated depressive symptoms (Patient Health Questionnaire$8 \geq 10$ ). We elicited medical history and current/past depression treatment use, attitudes (i.e., importance of dealing with MI-related stress, interest in talking about one's feelings (including if offered at no cost), and willingness by modality (defined as $\geq 3$ [very/somewhat interested] on a 4-point Likert scale): face-to-face counseling, antidepressants, group therapy

Received August 1, 2019

Accepted September 20, 2019

Published online October 28, 2019 (including social groups, e.g., exercise), remote therapy (telephone or video counseling), and self-help (here online or smartphone application-delivered). We used sampling weights based on 2010 NHIS age, gender, and race distributions of MI to calculate weighted percentages. Weighted multivariable logistic regression determined the association between key demographic characteristics (age, gender, race/ethnicity) and treatment willingness adjusting for income, education, and history of depression based on a priori hypotheses.

\section{RESULTS}

Overall, 352 (weighted percentage $23.7 \%$ ) of $1500 \mathrm{MI}$ participants had elevated depressive symptoms: average age (standard error) $59.6(0.69)$ years; $50.4 \%$ were female, and $23.9 \%$ non-white; $79.6 \%$ reported a history of hypertension, $78.7 \%$ high cholesterol, $47.3 \%$ heart failure, and $44.3 \%$ diabetes; $69.5 \%$ had prior depression (Table 1). Overall, $20.0 \%$ were currently receiving therapy, but $72.6 \%$ were somewhat/very interested in talking about their feelings and $95.2 \%$ felt it was important to deal with MI-related stress/feelings. Of 246 (71.2\%) individuals not offered counseling at the time of their MI, $74.2 \%$ would have gone if offered at no cost.

Overall, $88.3 \%$ of currently depressed post-MI survivors were willing to receive $\geq 1$ treatment modality; $72.1 \%$ face-to-face counseling, $58.8 \%$ antidepressant medication, $58.2 \%$ group-based treatment $(47.9 \%$ social groups like exercise/cooking; $45.7 \%$ group therapy), $48.8 \%$ remote $(42.1 \%$ phone counseling; $32.9 \%$ video), and $46.7 \%$ self-help ( $42.2 \%$ online materials; $21.9 \%$ apps) (Fig. 1). Individuals $\geq 65$ years old (vs. $<65$ years) were less willing to participate in $\geq 1$ modality $(80.1 \%$ vs. $93.1 \%, \mathrm{AOR}=0.27,95 \% \mathrm{CI} 0.11$ to 0.65 ), particularly face-to-face therapy $(62.1 \%$ vs. $78.2 \%$; $\mathrm{AOR}=0.54$, 95\% CI $0.31-0.95$ ), remote counseling ( $34.8 \%$ vs. $57.2 \%$; $\mathrm{AOR}=0.42,95 \% \mathrm{CI} 0.25-0.70)$, and self-help (35.1\% vs. $53.6 \% ; \mathrm{AOR}=0.47,95 \% \mathrm{CI}=0.28-0.81)$. Willingness 
Table 1 Characteristics and Attitudes of Adult Survivors of Myocardial Infarction (MI) with Elevated Symptoms of Depression

\begin{tabular}{|c|c|}
\hline Characteristic $(N=352)$ & $N($ weighted \%) \\
\hline \multicolumn{2}{|l|}{ Demographics } \\
\hline Age (year), $M(\mathrm{SD})$ & $59.6(0.69)$ \\
\hline Female & $178(50 \%)$ \\
\hline Non-Hispanic black & $54(14 \%)$ \\
\hline High school education or lower & $63(17.9 \%)$ \\
\hline Income of $<\$ 20,000$ & $83(25.4 \%)$ \\
\hline \multicolumn{2}{|l|}{ Self-reported MI history } \\
\hline Coronary artery bypass grafting & $230(64.0 \%)$ \\
\hline $\begin{array}{l}\text { (CABG), percutaneous transluminal } \\
\text { coronary angioplasty (PTCA) or stent }\end{array}$ & \\
\hline More than one prior MI & $144(40.9 \%)$ \\
\hline Number of MIs, $M$ (SE) & $1.9(0.1)$ \\
\hline \multicolumn{2}{|c|}{ Medical history (Has a doctor or nurse ever told you that you have...?) } \\
\hline High blood pressure (BP) & $285(79.6 \%)$ \\
\hline \multicolumn{2}{|l|}{ or hypertension } \\
\hline High blood cholesterol & $271(78.7 \%)$ \\
\hline Heart failure & $171(47.3 \%)$ \\
\hline Diabetes & $158(44.3 \%)$ \\
\hline Kidney problems (infection, stones, & $109(31.4 \%)$ \\
\hline \multicolumn{2}{|l|}{ nephritis, failure, stones, transplant, dialysis) } \\
\hline $\begin{array}{l}\text { Peripheral artery disease (clogged arteries in the } \\
\text { leos) }\end{array}$ & $77(20.8 \%)$ \\
\hline Stroke or transient ischemic attack (TIA) & $91(24.1 \%)$ \\
\hline \multicolumn{2}{|l|}{ Psychiatric history } \\
\hline Depression & $241(69.5 \%)$ \\
\hline Anxiety & $205(57.7 \%)$ \\
\hline Currently in therapy & $76(20 \%)$ \\
\hline At time of heart attack, offered counseling & $106(28.8 \%)$ \\
\hline $\begin{array}{l}\text { or talk therapy to talk about feelings related } \\
\text { to heart attack and coping? }\end{array}$ & \\
\hline \multicolumn{2}{|l|}{ Depression treatment attitudes } \\
\hline Interested in talking about feelings & $257(72.6)$ \\
\hline Important to deal with stress/feelings related & $333(95.2 \%)$ \\
\hline Important to recovery to take care of stress & $98(86.3 \%)$ \\
\hline $\begin{array}{l}\text { If counseling or talk therapy had been offered at } \\
\text { the time of your heart attack or now at no cost, } \\
\text { would you go? (of those not offered counseling at } \\
\text { time of heart attack }(n=246) \text { ) }\end{array}$ & $179(74.2 \%)$ \\
\hline
\end{tabular}

did not differ by gender but non-whites (vs. whites) were particularly interested in group therapy $(71.7 \%$ vs. $54.0 \%$, $\mathrm{AOR}=2.58,95 \% \mathrm{CI} 1.34-4.97)].->$

\section{DISCUSSION}

Depression treatment post-MI improves quality of life and perhaps long-term cardiac outcomes. We demonstrate that despite positive attitudes and general willingness, only $20 \%$ were currently in therapy, perhaps due to suboptimal guideline implementation/symptom recognition $(<30 \%$ were offered treatment peri-MI), low motivation (only $9 \%$ [self-help apps] to $40 \%$ [face-to-face therapy] were very interested), and access/cost (74\% would have gone if offered at no cost). Consistent with prior research, participants preferred face-to-face counseling, ${ }^{4}$ but we demonstrate that half would use remote modalities. Additionally, $90 \%$ were somewhat/very interested in $\geq 1$ modality, suggesting that expanding treatment options may result in higher engagement. Despite the emergence of mobile applications, however, interest in self-help apps was low, even in this online cohort.

This study was limited by retrospective, self-reported data, opt-in survey methodology, and inclusion of individuals with online access. Telehealth acceptability may also have shifted since survey conduct in 2013. Nonetheless, the majority of Americans use the Internet and we applied a rigorous survey methodology ${ }^{5}$ with response rates consistent with prior online surveys. Our results highlight the importance of patient preference, technology, and accessibility ${ }^{6}$ in depression treatment implementation among MI survivors. Further research is needed to understand gaps between generally positive treatment

\section{Acceptability for Depression Treatment Modalities in Depressed MyoCardial Infarction U.S. Adults}

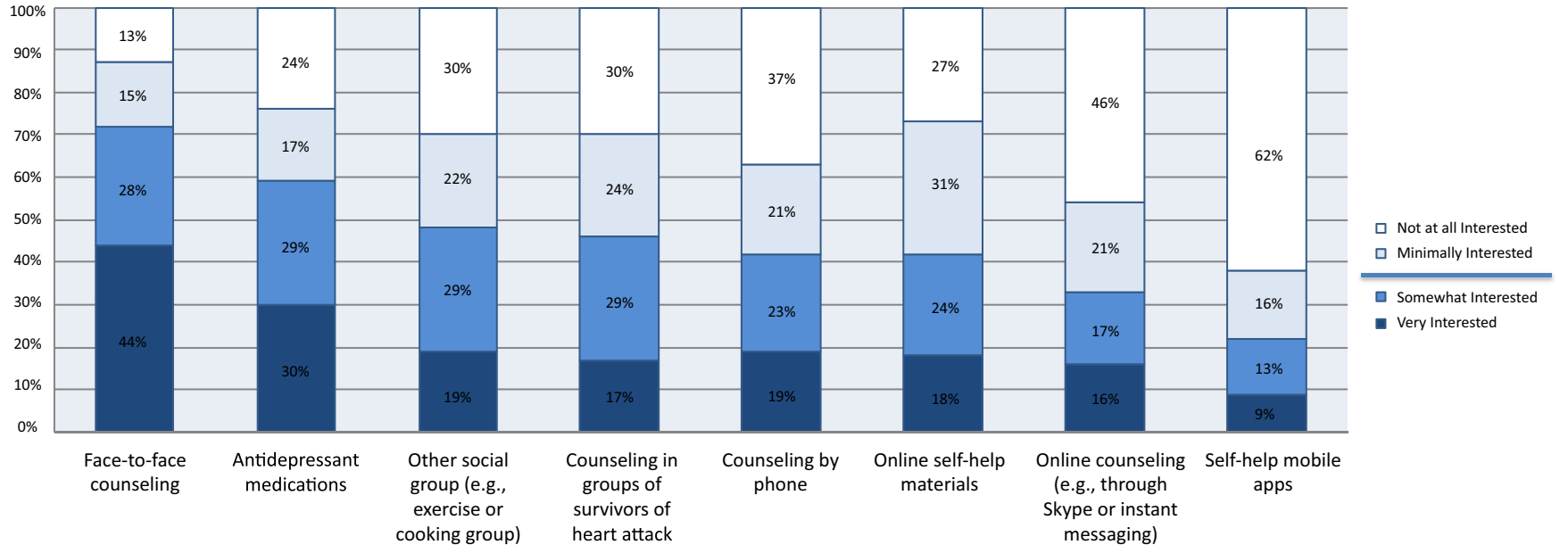

Figure 1 Willingness for depression treatment modalities among ever/currently depressed US adults with a history of myocardial infarction by age, gender, race/ethnicity. 
attitudes and low treatment initiation rates and to test engagement interventions, particularly in older MI patients.

Acknowledgments: We would like to acknowledge Karina Davison, $\mathrm{PhD}$; Joseph Schwartz, PhD; and Ian Kronish, MD, MS, for general supervision, editing, and support.

Corresponding Author: Nathalie Moise, MD, MS; Center for Behavioral Cardiovascular Health, Division of Cardiology, Department of MedicineColumbia University Medical Center, 622 W. 168th Street, PH9-Room 321, New York, NY 10032, USA (e-mail: nm2562@cumc. columbia.edu).

Author Contributions Study concept and design: Moise, Alcantara Acquisition of data: Alcantara

Analysis and interpretation of data: Moise, Thanataveerat, Alcantara, Ye

Drafting of the manuscript: Moise, Alcantara, Thanataveerat, Ye Critical revision of the manuscript for important intellectual content: Moise, Alcantara, Qian, Ye

Statistical analysis: Qian, Moise, Thanataveerat

Obtained funding: Alcantara

Study supervision: Moise

Funding Information This work was supported by funds from the National Institutes of Health (HL088117; HL114924; K23 HL121144; K23 HL-098359; 3 R01 HL114924-03S1; HL125748).

Data Availability Dr. Nathalie Moise had full access to all the data in the study and takes responsibility for the integrity of the data and the accuracy of the data analysis.

\section{Compliance with Ethical Standards:}

Conflict of Interest: The authors declare that they do not have a conflict of interest.
Disclaimer: The sponsors had no role in the design and conduct of the study, including the collection, management, analysis, and interpretation of the data; preparation, review, or approval of the manuscript; and decision to submit the manuscript for publication.

Publisher's Note: Springer Nature remains neutral with regard to jurisdictional claims in published maps and institutional affiliations.

\section{REFERENCES}

1. Lett HS, Blumenthal JA, Babyak MA, et al. Depression as a Risk Factor for Coronary Artery Disease: Evidence, Mechanisms, and Treatment. Psychosom Med. 2004;66(3):305-315.

2. Lichtman JH, Bigger JT, Blumenthal JA, et al. Depression and Coronary Heart Disease: Recommendations for Screening, Referral, and Treatment: A Science Advisory From the American Heart Association Prevention Committee of the Council on Cardiovascular Nursing, Council on Clinical Cardiology, Council on Epidemiology and Prevention, and Interdisciplinary Council on Quality of Care and Outcomes Research: Endorsed by the American Psychiatric Association. Circulation. 2008;118(17): 1768-1775.

3. Smolderen KG, Spertus JA, Gosch K, et al. Depression Treatment and Health Status Outcomes in Young Patients With Acute Myocardial Infarction: Insights From the VIRGO Study (Variation in Recovery: Role of Gender on Outcomes of Young AMI Patients). Circulation. 2017;135(18):1762-1764.

4. Van Voorhees BW, Cooper LA, Rost KM, Nutting P, Rubenstein LV, Meredith L, Wang NY and Ford DE. Primary care patients with depression are less accepting of treatment than those seen by mental health specialists. J Gen Intern Med. 2003; 18:991-1000.

5. Rivers D. Sample Matching: representative sampling from Internet Panels. YouGov Polimetrix. 2006. http://www.websm.org/uploadi/editor/ 1368187057Rivers_2006_Sample_matching_Representative_sampling_ from_Internet_panels.pdf. Accessed 5/19/2019.

6. Leng S, MacDougall $\mathbf{M}$ and McKinstry $\mathbf{B}$. The acceptability to patients of video-consulting in general practice: semi-structured interviews in three diverse general practices. J Innov Health Inform. 2016;23:141.

Publisher's Note Springer Nature remains neutral with regard to jurisdictional claims in published maps and institutional affiliations. 